\title{
The foundation and development of International Relations in Brazil - CORRIGENDUM
}

\author{
Carlos R. S. Milani* \\ Institute for Social and Political Studies, Rio de Janeiro State University, Rio de Janeiro, Brazil \\ ${ }^{\star}$ Corresponding author. E-mail: crsmilani@iesp.uerj.br
}

(First published online 16 April 2021)

doi: 10.1017/S0260210521000139, published online by Cambridge University Press, 29 March 2021.

The author has noticed a mistake in the Abstract and would like to rectify this to read as follows:

This article aims to contribute to the critical understanding of how International Relations (IR) was built as a social science field within Brazil's modern project. I argue that the foundation and the development of IR in Brazil in the twentieth century is closely associated with foreign policy, on the one hand, and with the national geopolitical thinking, particularly in the aftermath of the Second World War, on the other. In its trajectory, Brazil's IR has been influenced, among others, by the analysis of domestic and systemic determinants of foreign policy, historical interpretations, the study of the components of state power, studies of diplomacy and its contribution to the country's development, the analysis of decision-making processes and to a lesser extent, cognitive approaches. This article is organised around three sections. First, I discuss IR development in Brazil, stressing the role of diplomats, the key contribution of intellectuals coming from social and human sciences, and finally the emergence of the first generations of IR scholars in the eighties. Second, I present a brief history of the geopolitical tradition in Brazil's IR. Third, I analyse the institutionalisation of the field, its quantitative and qualitative growth, presenting some data on its organisation in recent times.

The author and Publisher apologise for this error.

\section{Reference}

Milani, C. R. S. 2021. The foundation and development of International Relations in Brazil. Review of International Studies X: 1-17. https://doi.org/10.1017/S0260210521000139

\footnotetext{
Cite this article: Milani, C. R. S. 2021. The foundation and development of International Relations in Brazil CORRIGENDUM. Review of International Studies 47, 618-618. https://doi.org/10.1017/S026021052100019X 